Research article

Open Access

\title{
Gene expression profiling in primary breast cancer distinguishes patients developing local recurrence after breast-conservation surgery, with or without postoperative radiotherapy
}

\author{
Emma Niméus-Malmström1, Morten Krogh2, Per Malmström1, Carina Strand1', Irma Fredriksson³, \\ Per Karlsson ${ }^{4}$, Bo Nordenskjöld 5 , Olle Stål5 ${ }^{5}$, Görel Östberg ${ }^{6}$, Carsten Peterson ${ }^{2}$ and \\ Mårten Fernö ${ }^{1}$
}

\author{
${ }^{1}$ Institute of Clinical Sciences, Department of Oncology, University Hospital, SE 22185 Lund, Sweden \\ ${ }^{2}$ Computational Biology and Biological Physics, Department of Theoretical Physics, Lund University, SE 22368 Lund, Sweden \\ ${ }^{3}$ Department of Surgery, Karolinska University Hospital in Solna, SE 17176 Stockholm, Sweden \\ 4Department of Oncology, Sahlgrenska University Hospital, SE 41345 Gothenburg, Sweden \\ 5Department of Clinical and Experimental Medicine, Division of Oncology, Linköping University, University Hospital, SE 58185 Linköping, Sweden \\ ${ }^{6}$ Department of Pathology, Halmstad Hospital, SE 30233 Halmstad, Sweden \\ Corresponding author: Mårten Fernö, Marten.Ferno@med.lu.se
}

Received: 8 Nov 2007 Revisions requested: 29 Nov 2007 Revisions received: 26 Feb 2008 Accepted: 22 Apr 2008 Published: 22 Apr 2008

Breast Cancer Research 2008, 10:R34 (doi:10.1186/bcr1997)

This article is online at: http://breast-cancer-research.com/content/10/2/R34

(c) 2008 Niméus-Malmström et al.; licensee BioMed Central Ltd.

This is an open access article distributed under the terms of the Creative Commons Attribution License (http://creativecommons.org/licenses/by/2.0), which permits unrestricted use, distribution, and reproduction in any medium, provided the original work is properly cited.

\begin{abstract}
Introduction Some patients with breast cancer develop local recurrence after breast-conservation surgery despite postoperative radiotherapy, whereas others remain free of local recurrence even in the absence of radiotherapy. As clinical parameters are insufficient for identifying these two groups of patients, we investigated whether gene expression profiling would add further information.
\end{abstract}

Methods We performed gene expression analysis (oligonucleotide arrays, 26,824 reporters) on 143 patients with lymph node-negative disease and tumor-free margins. A support vector machine was employed to build classifiers using leaveone-out cross-validation.

Results Within the estrogen receptor-positive $\left(E R^{+}\right)$subgroup, the gene expression profile clearly distinguished patients with local recurrence after radiotherapy $(n=20)$ from those without local recurrence ( $n=80$ with or without radiotherapy). The receiver operating characteristic $(\mathrm{ROC})$ area was 0.91 , and
5,237 of 26,824 reporters had a $P$ value of less than 0.001 (false discovery rate $=0.005$ ). This gene expression profile provides substantially added value to conventional clinical markers (for example, age, histological grade, and tumor size) in predicting local recurrence despite radiotherapy. Within the ER subgroup, a weaker, but still significant, signal was found (ROC area $=0.74$ ). The ROC area for distinguishing patients who develop local recurrence from those who remain local recurrence-free in the absence of radiotherapy was 0.66 (combined $\mathrm{ER}^{+} / \mathrm{ER}^{-}$).

Conclusion A highly distinct gene expression profile for patients developing local recurrence after breast-conservation surgery despite radiotherapy has been identified. If verified in further studies, this profile might be a most important tool in the decision making for surgery and adjuvant therapy.

\section{Introduction}

The addition of postoperative radiotherapy to breast-conservation surgery in patients with lymph node-negative breast cancer has been shown to reduce the 10-year risk of local recurrence from $29.2 \%$ to $10 \%$ [1]. However, more than half of the patients will never develop local recurrence whether given radiotherapy or not and a small proportion of the patients will develop local recurrence despite being given radiotherapy. Besides tumor-involved margins, generally accepted risk factors for the development of local recurrence are young age

$\mathrm{ER}=$ estrogen receptor; $\mathrm{ER}^{-}=$estrogen receptor-negative; ER+ = estrogen receptor-positive; GO = Gene Ontology; LR-RT- $=$no local recurrence, no radiotherapy given; $L R \cdot R^{+}=$no local recurrence after radiotherapy; $L R^{+} R T^{-}=$local recurrence developed, no radiotherapy given; $L R^{+} R^{+}=$local recurrence developed after radiotherapy; RIN = RNA integrity number; ROC = receiver operating characteristic; $\mathrm{SVM}=$ support vector machine. 
and multicentricity [2-5]. A number of other risk factors have been reported (for example, extensive intraductal component [6], family history [7], lymphovascular invasion [2,8-10], lobular cancer [11], and estrogen receptor-negative (ER-) status [10]), but their clinical usefulness so far is limited. If the patients who develop local recurrence despite radiotherapy can be identified, other treatment strategies should be considered. No factor hitherto has been found to be clinically useful for the identification of patients developing local recurrence after radiotherapy.

Gene expression analyses have been found to be useful for molecular subclassification of breast cancer and also have shown promising results for predicting distant recurrence [1217]. Concerning prediction of local recurrence, only a few studies have been reported. Cheng and colleagues [18] demonstrated two sets of gene expression profiles to be associated with local recurrence after mastectomy. Today, however, the majority of patients with breast cancer are operated on with breast-conservation surgery. As conventional risk factors for local recurrence after mastectomy differ from those after breast-conservation surgery, these findings may not be applicable when using less extensive surgery. Two recent studies included only patients treated with breast-conservation surgery: one was unable to find a distinguishing gene expression profile [19], whereas the other could only separate patients developing local recurrence after radiotherapy from patients not developing local recurrence by means of a predefined gene list, the wound-response signature [20]. This signature has been suggested to provide a possible link between cancer progression and wound healing and originally was defined as the fibroblast core serum response [21]. The material in the study by Nuyten and colleagues [20] was heterogeneous with regard to margin status, ER status, lymph node status, adjuvant systemic treatment (47\% with and $53 \%$ without), and radiotherapy (including both standard and boost treatment). This heterogeneity might be the reason for not finding a significant gene profile in this study when using the whole set of genes. As far as the importance of considering ER status in gene expression analyses, today it is generally accepted that $\mathrm{ER}^{+}$and $\mathrm{ER}$ - breast tumors have remarkably distinct gene expression profiles $[22,23]$ and this subdivision of ER status has been successfully applied when predicting distant recurrence $[14,24]$.

Our study aimed at elucidating whether gene expression analysis is useful in predicting tumor sensitivity to radiotherapy and capacity to develop local recurrence in a patient material homogenous with regard to tumor-free margins, lymph node status, and radiotherapy (only standard doses). A predictive gene expression profile might impact the choice of both surgery and radiotherapy. A hypothetical clinical routine scheme, demonstrating three treatment options, is outlined in Figure 1. After a preoperative analysis of the gene expression profile, the first step is to identify the patients who will develop local recur-
Figure 1

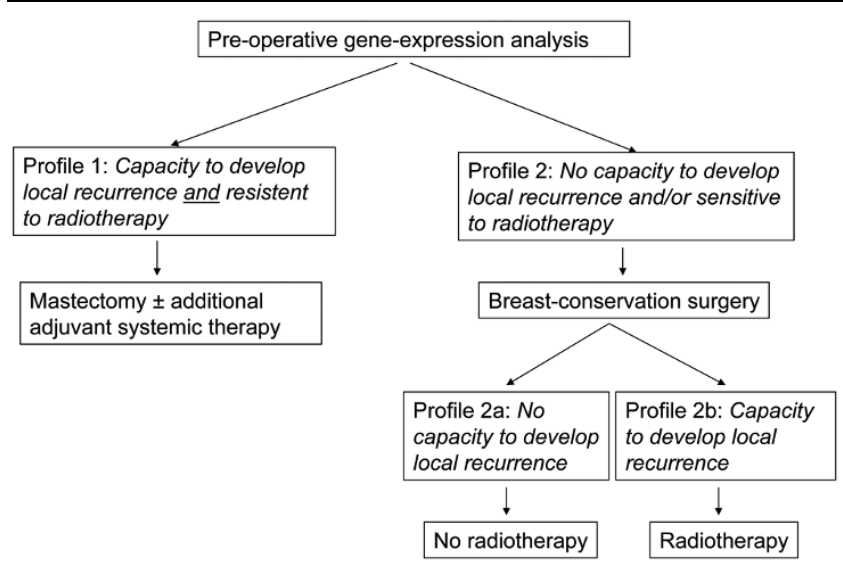

A hypothetical clinical routine scheme for the choice of surgery and radiotherapy after preoperative gene expression analysis.

rence despite radiotherapy. For this group, mastectomy might be a better choice. The second step is to separate those patients with no capacity to develop local recurrence and therefore not in need of radiotherapy after breast-conservation surgery from those with a capacity to develop local recurrence and in need of radiotherapy.

\section{Materials and methods Patients}

Study design, inclusion criteria, and sample collection

Frozen tumor samples were collected from patients representing the following four groups: (a) LR+RT+ (local recurrence developed after radiotherapy), (b) LR-RT+ (no local recurrence after radiotherapy), (c) LR+RT- (local recurrence developed, no radiotherapy given), and (d) LR-RT- (no local recurrence, no radiotherapy given). All patients were operated on with breastconservation surgery and axillary clearance with no lymph node involvement, tumor size of less than or equal to $30 \mathrm{~mm}$ (two patients had tumors measuring 32 and $40 \mathrm{~mm}$, respectively, and one was T2 without any further information on size), tumor-free margins $(>1 \mathrm{~mm})$, no multicentricity, and with frozen tumor tissue with good RNA quality available. Local recurrence was defined as the appearance of a new breast tumor in the ipsilateral residual breast parenchyma in the overlying skin or in the scar. Patients with recurrence in the contralateral breast or with distant metastases prior or simultaneous to local recurrence were excluded. In the first inclusion, 102 patients from a randomized clinical trial in the South and West health care regions in Sweden [25] and 19 patients from a population-based cohort study with a nested case-control study (Stockholm and South Sweden) $[3,26]$ were included (Tables 1 and 2). To perform gene expression profiling in a more homogenous material with regard to ER status and yet with a sufficient number of cases in all four subgroups, 22 additional $\mathrm{ER}^{+}$tumors from the South-East and South health care regions were included in a second inclusion (Tables 1 and 2). The study was approved by the Ethics Committee at Lund 
Table 1

Clinical and pathological characteristics of the 77 patients receiving radiotherapy, with or without the development of local recurrence

\begin{tabular}{|c|c|c|c|}
\hline All & \multicolumn{2}{|c|}{$\mathrm{LR}^{+} \mathrm{RT}^{+}$} & LR-RT+ \\
\hline Time to local recurrence, months & \multicolumn{2}{|c|}{$\mathrm{n}=30$} & $\mathrm{n}=47$ \\
\hline \multicolumn{4}{|l|}{ Median } \\
\hline Range & \multicolumn{2}{|c|}{50} & - \\
\hline Follow-up, months & \multicolumn{2}{|c|}{$8-149$} & - \\
\hline \multicolumn{4}{|l|}{ Median } \\
\hline Range & \multicolumn{2}{|c|}{ - } & 85 \\
\hline Tamoxifen & \multicolumn{2}{|c|}{-} & $62-231$ \\
\hline Chemotherapy & \multicolumn{2}{|c|}{6} & 1 \\
\hline Tamoxifen and chemotherapy & \multicolumn{2}{|c|}{0} & 0 \\
\hline \multirow[t]{2}{*}{ No adjuvant treatment } & \multicolumn{2}{|c|}{0} & 0 \\
\hline & \multicolumn{2}{|c|}{24} & 46 \\
\hline Inclusion 1 and 2 & Inclusion 1 & Inclusion 2 & Inclusion 1 \\
\hline \multicolumn{4}{|l|}{ Menopause } \\
\hline Pre & 12 & 5 & 13 \\
\hline Post & 7 & 1 & 33 \\
\hline Not available & 0 & 5 & 1 \\
\hline \multicolumn{4}{|l|}{ Age at operation, years } \\
\hline Median & 48 & 47 & 57 \\
\hline Range & $27-63$ & $34-73$ & $33-73$ \\
\hline \multicolumn{4}{|l|}{ Size, millimeters } \\
\hline Median & 14 & 15 & 15 \\
\hline Range & $2-32$ & $10-20$ & $4-22$ \\
\hline Not available & 0 & $2^{\mathrm{a}}$ & 0 \\
\hline \multicolumn{4}{|l|}{ Grade } \\
\hline 1 & 3 & 3 & 22 \\
\hline 2 & 8 & 6 & 13 \\
\hline 3 & 7 & 1 & 10 \\
\hline Not available & 1 & 1 & 2 \\
\hline \multicolumn{4}{|l|}{ Estrogen receptor } \\
\hline Positive & 9 & 11 & 42 \\
\hline Negative & 10 & 0 & 5 \\
\hline \multicolumn{4}{|l|}{ Progesterone receptor } \\
\hline Positive & 5 & 9 & 31 \\
\hline Negative & 13 & 2 & 11 \\
\hline Not available & 1 & 0 & 5 \\
\hline \multicolumn{4}{|l|}{ Health care region } \\
\hline South & 8 & 2 & 30 \\
\hline
\end{tabular}


Table 1 (Continued)

Clinical and pathological characteristics of the 77 patients receiving radiotherapy, with or without the development of local recurrence

\begin{tabular}{llll}
\hline West & 2 & 0 & 9 \\
South-East & 0 & 9 & 0 \\
Stockholm & 9 & 0 & 8 \\
\hline
\end{tabular}

a One $\mathrm{T} 1$ and one $\mathrm{T} 2 . \mathrm{LR}^{-} \mathrm{RT}^{+}=$no local recurrence after radiotherapy; $\mathrm{LR}^{+} \mathrm{RT} T^{+}=$local recurrence developed after radiotherapy.

University (Lund, Sweden). Patient and primary tumor characteristics and follow-up information were collected from the patients' medical records.

\section{Treatment}

Postoperative radiotherapy with a median absorbed dose of 50 Gy (range 48 to 54 Gy) was given in 24 to 27 fractions in one series to the remaining breast parenchyma. Adjuvant systemic therapy was given to 16 patients (Tables 1 and 2).

\section{Conventional factors}

Histological grade was re-evaluated according to Elston and Ellis [27]. ER and progesterone receptor content were analyzed routinely after primary operation with enzyme immunoassay according to kit instructions (Abbott Laboratories, Diagnostics Division, Chicago, IL, USA) and expressed as femtomoles per milligram of cytosol protein. Receptor values greater than or equal to $25 \mathrm{fmol} / \mathrm{mg}$ protein were considered positive.

\section{Gene expression analysis}

RNA was extracted from freshly frozen invasive breast tumors as previously described [28]. The RNA quality was assessed using an Agilent 2100 Bioanalyzer (Agilent Technologies, Santa Clara, CA, USA), and the RNA integrity number (RIN) method [29] was used to validate the RNA quality. Twenty-one samples were excluded due to RIN values of below 6 . Labeling and hybridization were performed as previously described [28]. By means of Human Genome Oligo Set Version 2.1 (containing 21,329 70-mer probes) and Human Genome Oligo Set Version 2.1 Upgrade 27 (containing 5,462 70-mer probes), oligonucleotide arrays were produced by the Swegene DNA Microarray Resource Centre, Lund University [30]. In inclusion step 1, probes were printed in duplicate, creating $55 \mathrm{~K}$ slides, and in inclusion step 2, in single, creating $27 \mathrm{~K}$ slides.

\section{Statistics}

Wilcoxon rank sum tests, Sammon maps, and support vector machine (SVM) classifications [31] were performed with the statistical language $R$ [32] using the libraries MASS (Sammon) and e1071 (SVM). For the SVM, only genes with no missing values were used. For the $\mathrm{LR}^{+} \mathrm{RT}^{+}$versus $L \mathrm{R}^{-} \mathrm{RT}+/ \mathrm{LR}^{-}$ RT- groups, the numbers of genes with no missing values were $9,128,13,362$, and 8,834 for the ER+ ${ }^{+}, E R$, and combined ER groups, respectively. For the LR+RT- versus LR-RT- groups, they were $11,209,13,547$, and 10,658 , respectively. For the wound-response genes, the corresponding numbers were 93 , 120 , and 91 for the $L R^{+} \mathrm{RT}^{+}$versus LR-RT+/LR-RT- groups and 105,122 , and 99 for the LR+RT- versus LR-RT- groups. Leaveone-out cross-validation was used. When a sample was left out, the SVM was trained on the remaining samples, and the distance to the maximal margin hyperplane (the decision value) was calculated for the left-out sample. A linear kernel was used and the cost of constraints violation ( $C$ constant) was fixed to one. No parameter tuning was performed even if the use of another layer of cross-validation might have improved the results. The goal of this study was to prove that gene expression profiles can distinguish the groups, not to find the optimal classifier. Actually, the optimal classifier does not even need to be an SVM. We also minimized potential suspicions about information leak by restricting the parameters of the SVM to the default values of the $R$ function svm. A receiver operating characteristic (ROC) curve and area were calculated using the decision values. The expected average value of the ROC area is 0.5 if there is no discrimination between the groups. Due to random variations, $\mathrm{ROC}$ areas above 0.5 are often obtained even when there is no discrimination between the groups. To distinguish a real discrimination between the groups from the case of no discrimination, a p-value was calculated. A small $p$-value makes it unlikely that the ROC area can be reconciled with the case of no discrimination. The $p$ value was calculated by a permutation test. The local recurrence labels were shuffled randomly 1,000 times and the ROC areas were found for the corresponding classifications. The $P$ value was calculated as the fraction of the 1,000 permutations that had an ROC area larger than the real one. If the $P$ value was zero, the random ROC areas were fitted to a normal distribution and the area under the tail above the real ROC area was used as the $P$ value. The $P$ value of the ROC area for the case of a fixed test set (that is, no cross-validation) was calculated by a permutation test of the labels in the test set. Odds ratios, confidence intervals of odds ratios, and $P$ values of odds ratios were calculated with the $\mathrm{R}$ function Fisher test, which uses the conditional maximum likelihood estimator.

\section{Gene Ontology}

The Gene Ontology (GO) [33] OBO (open biomedical ontologies) file of 14 November 2006 was used. Gene annotation was performed using ACID (Array Clone Information Database), which is a publicly available web application that provides GO categories for genes [34]. A total of 6,841 GO 
Table 2

Clinical and pathological characteristics of the 66 patients, not receiving radiotherapy, with or without the development of local recurrence

\begin{tabular}{|c|c|c|c|}
\hline \multirow[t]{2}{*}{ All } & LR+RT- & \multicolumn{2}{|c|}{ LR-RT- } \\
\hline & $\mathrm{n}=22$ & \multicolumn{2}{|c|}{$\mathrm{n}=44$} \\
\hline \multicolumn{4}{|l|}{ Time to local recurrence, months } \\
\hline Median & 35 & \multicolumn{2}{|c|}{ - } \\
\hline Range & $11-96$ & \multicolumn{2}{|c|}{-} \\
\hline \multicolumn{4}{|l|}{ Follow-up, months } \\
\hline Median & - & \multicolumn{2}{|c|}{84} \\
\hline Range & - & \multicolumn{2}{|c|}{$21-166$} \\
\hline Tamoxifen & 2 & \multicolumn{2}{|c|}{4} \\
\hline Chemotherapy & 1 & \multicolumn{2}{|c|}{1} \\
\hline Tamoxifen and chemotherapy & 1 & \multicolumn{2}{|c|}{0} \\
\hline No adjuvant treatment & 18 & \multicolumn{2}{|c|}{39} \\
\hline Inclusion 1 and 2 & Inclusion 1 & Inclusion 1 & Inclusion 2 \\
\hline \multicolumn{4}{|l|}{ Menopause } \\
\hline Pre & 9 & 3 & 4 \\
\hline Post & 13 & 30 & 2 \\
\hline Not available & 0 & 0 & 5 \\
\hline \multicolumn{4}{|l|}{ Age at operation, years } \\
\hline Median & 53 & 61 & 49 \\
\hline Range & $44-73$ & $45-70$ & $40-62$ \\
\hline \multicolumn{4}{|l|}{ Size, millimeters } \\
\hline Median & 15 & 13 & 16 \\
\hline Range & $7-30$ & $6-40$ & $10-26$ \\
\hline Not available & 0 & 0 & 0 \\
\hline \multicolumn{4}{|l|}{ Grade } \\
\hline 1 & 4 & 13 & 5 \\
\hline 2 & 10 & 9 & 3 \\
\hline 3 & 5 & 8 & 3 \\
\hline Not available & 3 & 3 & 0 \\
\hline \multicolumn{4}{|l|}{ Estrogen receptor } \\
\hline Positive & 14 & 27 & 11 \\
\hline Negative & 8 & 6 & 0 \\
\hline \multicolumn{4}{|l|}{ Progesterone receptor } \\
\hline Positive & 15 & 17 & 11 \\
\hline Negative & 7 & 14 & 0 \\
\hline Not available & 0 & 2 & 0 \\
\hline \multicolumn{4}{|l|}{ Health care region } \\
\hline South & 9 & 21 & 11 \\
\hline
\end{tabular}


Table 2 (Continued)

Clinical and pathological characteristics of the 66 patients, not receiving radiotherapy, with or without the development of local recurrence

\begin{tabular}{lccc}
\hline West & 13 & 10 & 0 \\
South-East & 0 & 0 & 0 \\
Stockholm & 0 & 2 & 0 \\
\hline
\end{tabular}

$\mathrm{LR} \cdot \mathrm{RT}-=$ no local recurrence, no radiotherapy given; $\mathrm{LR}^{+} \mathrm{RT}-=$ local recurrence developed, no radiotherapy given.

categories belonging to 'Cellular component', 'Biological process', or 'Molecular function' had at least one gene in common with our data. The genes were ranked according to their Wilcoxon rank sum $P$ value between $\mathrm{LR}^{+} \mathrm{RT}^{+}$and $\mathrm{LR}^{-} \mathrm{RT}^{+} / \mathrm{LR}^{-}$ RT- groups in the $\mathrm{ER}^{+}$group. A Wilcoxon rank sum test was performed for each GO category to test for over-representation of genes toward the top of the ranked gene list using Catmap [35].

\section{Results}

\section{Patients with a capacity to develop local recurrence despite radiotherapy}

To identify this group of patients, we compared $L R+R T+$ versus LR-RT+/LR-RT- groups. There was an association between the $\mathrm{LR}^{+} \mathrm{RT}^{+}$group and ER- status (odds ratio 6.8, 95\% confidence interval 2.0 to $24 ; P=0.0007$ ) (Table 3 ). In this analysis, only the patients from the first inclusion were used, as the second inclusion was made on ER and local recurrence status. Age can also distinguish the $\mathrm{LR}^{+} \mathrm{RT}+$ group. Histological grade was marginally able to separate the $\mathrm{LR}^{+} \mathrm{RT}^{+}$group from the $\mathrm{LR}^{-}$ $\mathrm{RT}^{+} / \mathrm{LR}-\mathrm{RT}$ - group, whereas tumor size was not (Table 3 ).
After filtering the microarray data on low-quality spots and missing values, 26,824 reporters remained, representing 16,895 unique genes. From a Sammon map of the gene expression profiles of the $100 \mathrm{ER}^{+}$patients from both inclusions, it was evident that the LR+RT+ and LR-RT+/LR-RTgroups were well separated even without gene selection (Figure 2). For supervised classification, an SVM was used. The areas under the receiver operating curve (ROC areas) were $0.91\left(P=9 \times 10^{-6}\right)$ within the $\mathrm{ER}^{+}$group, $0.74(P=0.08)$ within the ER- group (Figure 3), and $0.83\left(P=9 \times 10^{-5}\right)$ within the combined ER+/ER- group (data not shown). The ER ${ }^{+}$group was by far the larger group, which could explain the superior performance of the $\mathrm{ER}^{+}$group compared with the ER- one. Also, the classification performance was deteriorated by combining $\mathrm{ER}^{+}$and $\mathrm{ER}^{-}$in one SVM; it was preferable to use distinct SVMs for the two subpopulations (Figure 3). For the $\mathrm{ER}^{+}$ group, at $90 \%$ sensitivity (18 of $20 \mathrm{LR}^{+} \mathrm{RT}^{+}$correctly classified), the specificity was $87.5 \%$ (70 of 80 LR-RT+/LR-RT- correctly classified), and at $90 \%$ specificity (72 of $80 \mathrm{LR}^{-R T}+/ \mathrm{LR}^{-}$ RT- correctly classified), the sensitivity was $80 \%$ (16 of 20 $\mathrm{LR}^{+} \mathrm{RT}+$ correctly classified).

Table 3

\begin{tabular}{|c|c|c|c|}
\hline Factor & $\mathrm{LR}^{+} \mathrm{RT}^{+}$ & LR-RT+/LR-RT- & $P$ value \\
\hline \multicolumn{4}{|l|}{ ER status, number } \\
\hline Negative & 10 & 11 & \\
\hline Positive & 9 & 69 & $0.0007^{a}$ \\
\hline \multicolumn{4}{|l|}{ Median age, years } \\
\hline All & 48 & 61 & $0.00004^{b}$ \\
\hline ER- subgroup & 49.5 & 53 & 0.12 \\
\hline $\mathrm{ER}^{+}$subgroup & 46 & 61 & 0.002 \\
\hline \multicolumn{4}{|l|}{ Histological grade, number } \\
\hline 1 & 3 & 35 & \\
\hline 2 & 8 & 22 & \\
\hline 3 & 7 & 18 & $0.055^{a}$ \\
\hline Median tumor size, millimeters & 15 & 15 & $0.95 b$ \\
\hline
\end{tabular}

Only cases from inclusion 1 are included. aFisher exact test. bWilcoxon rank sum test. ER = estrogen receptor; LR-RT- $=$ no local recurrence, no radiotherapy given; LR $\mathrm{RT}^{+}=$no local recurrence after radiotherapy; LR+RT+= local recurrence developed after radiotherapy. 
Figure 2

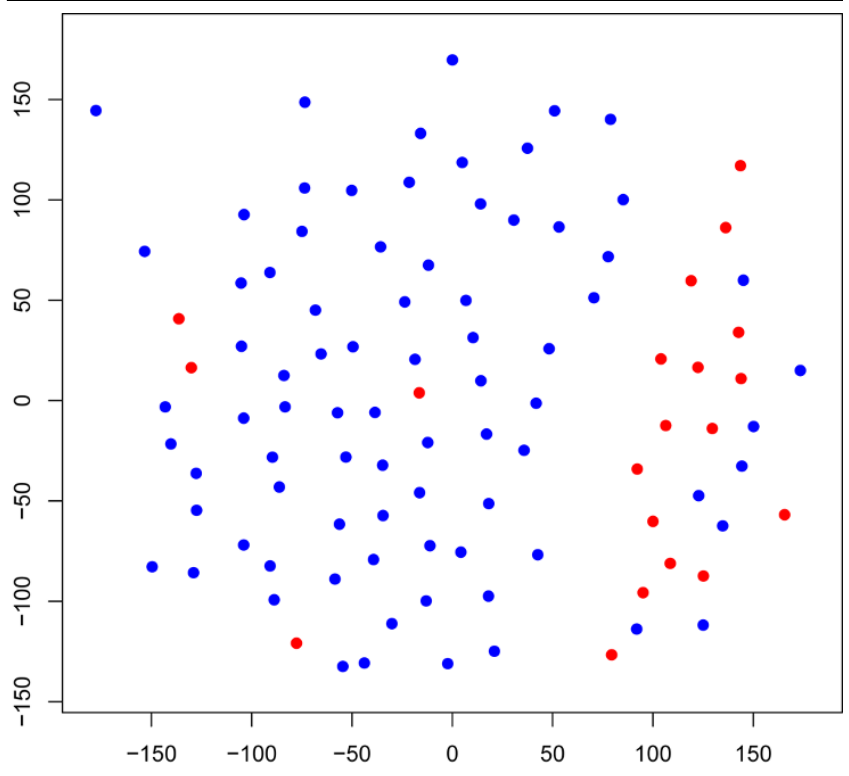

A Sammon map of the 100 estrogen receptor-positive patients within the $\mathrm{LR}^{+} \mathrm{RT}^{+}$group (red dots, 20 patients) and the LR-RT+/LR-RT- group (blue dots, 80 patients). The Sammon map was performed with all 26,824 reporters. Euclidean distance in $\log _{2}$ expression values was used as the distance measure. LR-RT- $=$ no local recurrence, no radiotherapy given; $\mathrm{LR}^{\mathrm{R}} T^{+}=$no local recurrence after radiotherapy; $\mathrm{LR}^{+} \mathrm{RT}^{+}$ $=$ local recurrence developed after radiotherapy.

As age is a risk factor for local recurrence, we investigated whether the gene expression profiling has classification ability beyond that of age in the $\mathrm{ER}^{+}$subgroup. We constructed a training set from the 77 patients who were either older than 50 years and in the LR-RT+/LR-RT- group or younger than 50 years and in the $\mathrm{LR}^{+} \mathrm{RT}^{+}$group. The test set consisted of the remaining 23 patients (for example, those who were either younger than 50 years and in the LR-RT+/LR-RT- group or older than 50 years and in the LR+RT+ group). The point is that the test set chosen contains patients who behave exactly opposite to the usual connection between age and local recurrence. Applying an SVM, we obtained an ROC area of 0.88 ( $P=$ 0.002). Furthermore, we checked the influence of health care regions by using the 68 samples from the South and SouthEast health care regions as a training set and the 32 samples from the West or Stockholm health care regions as a test set. The specific split into health care regions was done to get a reasonable amount of samples in $\mathrm{LR}^{+} \mathrm{RT}{ }^{+}$and $\mathrm{LR}-\mathrm{RT}+/ \mathrm{LR}-\mathrm{RT} \mathrm{T}^{-}$ groups in both the training and the test set. No optimizations were performed in this regard. The ROC area of $0.87(P=$ 0.002 ) shows that the classifier indeed works across health care regions.

The wound-response signature genes, also known as the core serum response genes [21], were shown to have the ability of partially predicting local recurrence [20]. We mapped the wound-response signature to our microarrays and performed an SVM classification using only this signature. The ROC areas were $0.75(P=0.007)$ within the $\mathrm{ER}^{+}$group, $0.75(P=$ $0.08)$ within the ER group, and $0.61(P=0.10)$ within the combined ER+/ER' group.

\section{Differentially expressed genes}

A Wilcoxon rank sum test between $\mathrm{LR}^{+} \mathrm{RT}^{+}$and $\mathrm{LR}-\mathrm{RT}^{+} / \mathrm{LR}^{-}$ $\mathrm{RT}^{-}$groups within the $\mathrm{ER}^{+}$subgroup was performed for all 26,824 reporters. A clear over-representation of genes with small $P$ values was found; for example, there are 5,237 reporters with a $P$ value below 0.001 corresponding to a BenjaminiHochberg [36] false discovery rate of 0.005 . A heatmap of the 81 genes with a known gene name, no missing values, and a Wilcoxon rank sum test $P$ value between the $\mathrm{LR}^{+} \mathrm{RT}^{+}$and $\mathrm{LR}^{-}$ $\mathrm{RT}^{+} / \mathrm{LR} \mathrm{RT}^{-}$groups of below $10^{-6}$ is shown in Figure 4. A GO analysis was performed using Catmap [35]. A total of 6,841 $\mathrm{GO}$ categories belonging to 'Cellular component', 'Biological process', or 'Molecular function' were included. At a false discovery rate of 0.05 , only the four categories of cytosolic ribosome (sensu Eukaryota), eukaryotic 43S preinitiation complex, eukaryotic $48 \mathrm{~S}$ initiation complex, and cytosolic small ribosomal subunit (sensu Eukaryota) were significant.

\section{Patients with no capacity to develop local recurrence}

To identify this group of patients, we analyzed LR+RT- versus LR-RT- groups. ER- status was weakly correlated with the LR+RT- group (odds ratio 2.5, 95\% confidence interval 0.6 to $11 ; P=0.21$ ) (Table 4). Young age was correlated with local recurrence in the $\mathrm{ER}^{+}$group (Table 4). Neither histological grade nor tumor size had the power to separate the two groups.

An SVM gene expression classifier yielded an ROC area of $0.66(P=0.04)$ within the combined ER+/ER- group. The ER and $\mathrm{ER}^{+}$subgroups were too small to give a significant result on their own, even though there was a tendency of discriminative power within the ER+ subgroup. (ROC area $=0.62 ; P=$ $0.14)$. For the wound-response signature, the ROC areas were $0.64(P=0.10)$ in the $\mathrm{ER}^{+}$group, $0.69(P=0.27)$ in the ER- group, and $0.68(P=0.03)$ in the combined group.

\section{Discussion}

We have found a highly significant gene expression profile associated with the development of local recurrence after breast-conservation surgery despite postoperative radiotherapy. If patients resistant to radiotherapy can be identified, they should be candidates for alternative treatment strategies such as mastectomy, other adjuvant treatments, and/or higher radiation doses as local recurrence implies an increased risk of both distant metastases and mortality [37-39]. So far, there are no markers useful in the clinic for the identification of radioresistant breast cancer. We found both age and ER status to be associated with local recurrence after radiotherapy. However, our gene expression signature provides substantially added value to these factors and also to histological grade and tumor size. A hybrid classifier of age and gene expression 



Receiver operating characteristic (ROC) curves for the support vector machine classification of $L R^{+} R T^{+}$versus LR-RT+/LR-RT- groups within the estrogen receptor-positive (ER+) group (left part) and estrogen receptor-negative (ER-) group (right part). The specificity is defined as the fraction of the LR-RT+/LR-RT- patients correctly classified, and the sensitivity as the fraction of the $\mathrm{LR}^{+} \mathrm{RT}^{+}$patients correctly classified. $\mathrm{LR}^{-R T}=\mathrm{R}^{-}=$no local recurrence, no radiotherapy given; $L R \cdot R T^{+}=$no local recurrence after radiotherapy; $\mathrm{LR}^{+} \mathrm{RT} T^{+}=$local recurrence developed after radiotherapy.

should perform even better than age or gene expression alone. Due to the sample size in this study, we did not have the possibility to build such a hybrid classifier. We have focused on the question of whether gene expression analysis per se is useful for the identification of patients with different risks of developing local recurrences. A thorough and more specific evaluation of the gene list should be performed after a confirmative study in which not only the genes, but also the pathways in which they are involved, are considered. The high proportion of ribosomal-related genes is noteworthy but also needs to be confirmed. The samples were collected from four health care regions with different routines for handling fresh tumor tissue prior to freezing. However, we could clearly demonstrate that these differences did not influence the importance of the gene expression signature.

To our knowledge, only one previous study has reported a gene expression signature significantly associated with local recurrence after breast-conservation surgery [20], but only when using a predefined wound-response signature gene list. One reason for not finding a significant profile when using the entire gene set may be that their material, which included 17 local recurrences, was more heterogeneous than ours with regard to tumor-free margins, tumor size, lymph node status, and dose of radiotherapy. Furthermore, they did not separate the samples with regard to ER status. $\mathrm{ER}^{+}$and ER- breast tumors are known to have distinct gene expression profiles and indeed we found a stronger gene expression profile when including only $\mathrm{ER}^{+}$tumors compared with when ER- tumors were included (ROC area 0.91 compared with 0.83). This finding further strengthened the notion that ER+ and ER- breast cancer should be handled as two separate entities when evaluating gene expression data, as has previously been stated by authors in analyses of gene expression profiles associated with distant metastases $[14,24,40]$. In our material, the wound-response signature genes were able to predict local recurrence within both the $\mathrm{ER}^{+}$group and ER- group with reasonable accuracy, whereas the prediction in the combined group was rather weak. For the $\mathrm{ER}^{+}$group and the combined group, the classification performance is inferior to the results obtained with all genes. This degradation of performance shows that the advantage of restricting the gene set used in the classifier to the focused set of wound-response signature genes, which are known to be relevant to cancer, is outweighed by the loss of information of discarding the majority of the genes. The reason that the SVM using all genes was so much better at classifying the combined group than the wound-response signature genes is probably that the ER signal is contained in the full gene set but is more or less absent in the wound-response signature genes. With respect to individual samples, it is seen that the samples that were misclassified with all genes were also misclassified with the woundresponse signature genes but that many of the misclassified samples with the wound-response signature genes were correctly classified with all genes.

For the identification of patients with no capacity to develop local recurrence, we compared the LR+RT- and LR-RT- subgroups. The gene expression signal was weaker, but still significant $(\mathrm{ROC}$ area $=0.66$ ). The reason for a weaker signal 
Figure 4
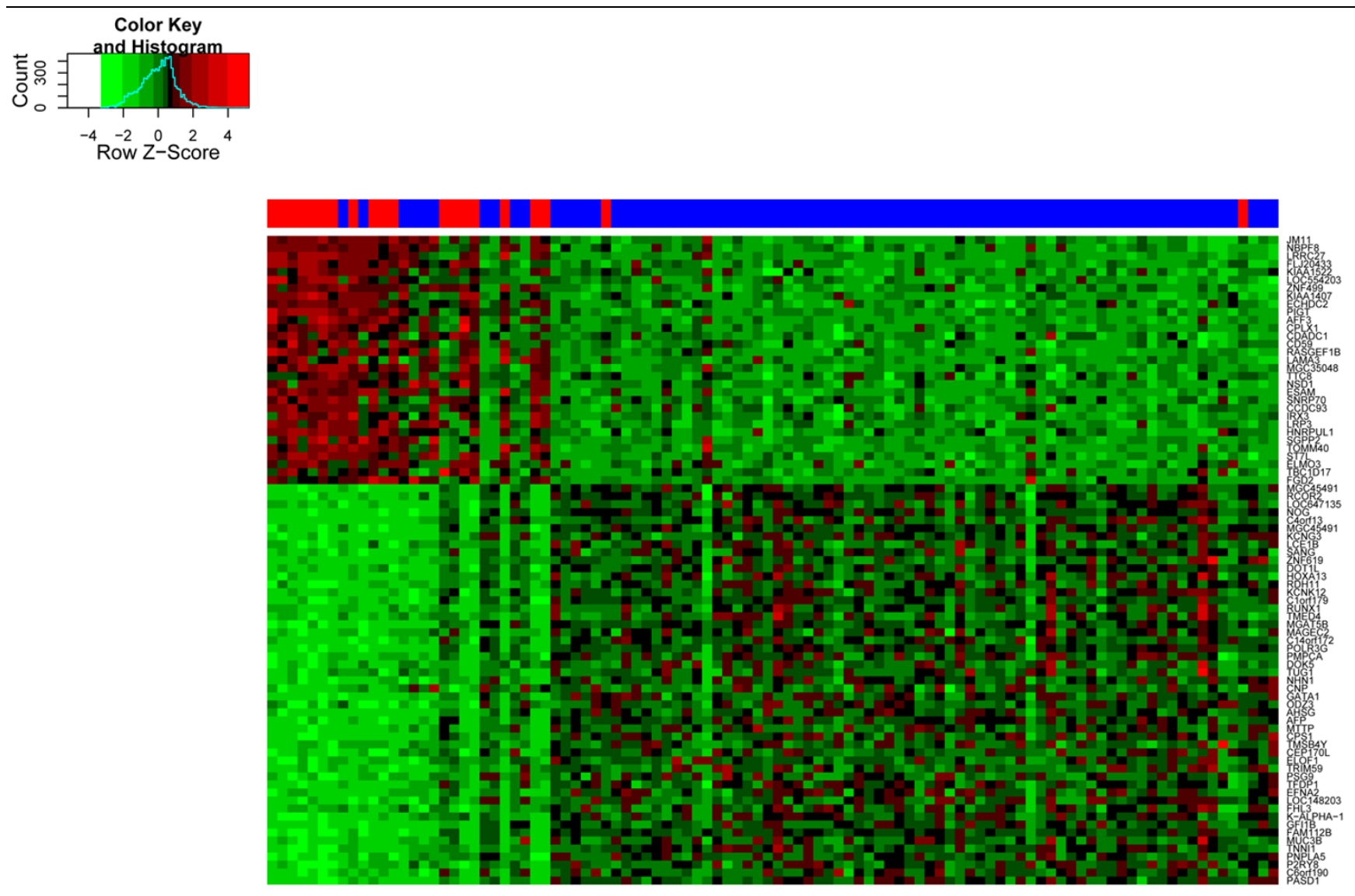

The 81 most important genes. A heatmap of 81 genes (rows) and 100 patients (columns) with patients ordered according to their leave-one-out support vector machine classification value: estrogen receptor-positive patients within $L R^{+} R T^{+}($red, $n=20)$ and LR-RT+/LR-RT- $(b l u e, n=80)$ groups. The gene selection and ordering are described in the text. Expression values are logarithmically transformed, centered around zero, and nor-

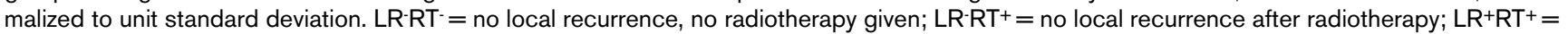
local recurrence developed after radiotherapy.

may be the small number of patients $(n=66)$. For the woundresponse genes, there is a tendency for correct predictions, but the results are too weak to draw any conclusions. More samples would be needed to test it further.

Today, the vast majority of breast cancer patients are treated with radiotherapy after breast-conservation surgery to lower the risk of local recurrence. However, a large proportion of these patients have a very low risk for local recurrence, and the positive effects must be weighed against costs and side effects of the treatment. The identification of patients with a very low risk to develop local recurrence, and consequently not in need of postoperative radiotherapy, is of great clinical importance.

No patient included in our study had tumor-involved margins, a risk factor for local recurrence. The local recurrence rate is influenced by the amount of uninvolved breast parenchyma surrounding the tumor as higher recurrence rates have been reported after lumpectomy [41] than after sector resection
[25] or quadrantectomy [42]. With smaller resection margins, microscopic residual tumor is more likely to be present in the breast and the administered radiotherapy dose may be too low to give complete protection for local recurrence. Thus, it cannot be excluded that the gene expression profile can be influenced by resection margins.

Our gene expression profile was associated with local recurrence after radiotherapy at commonly used doses. Higher doses of radiation, with a boost of 16 Gy, have been shown to significantly reduce the local recurrence rate, particularly in patients below 50 years of age [43]. Unfortunately, higher radiation doses cause a less satisfactory cosmetic result [44]. Whether gene profiling also can be used for identification of patients in need of a boost is unclear at present.

One might speculate why the gene expression profile method performs significantly better for the prediction of local recurrence than for the prediction of distant metastasis. It is possible that the gene profile associated with the development of 
Table 4

A comparison between the LR+RT- and LR-RT- subgroups

\begin{tabular}{lccc}
\hline Factor & LR+RT $^{-}$ & LR-RT- & $P$ value \\
\hline $\begin{array}{l}\text { ER status, number } \\
\quad \text { Negative }\end{array}$ & 8 & 6 & \\
$\quad$ Positive & 14 & 27 & $0.21^{\mathrm{a}}$ \\
Median age, years & & & \\
$\quad$ All & 53 & 61 & $0.02^{\mathrm{b}}$ \\
ER- subgroup & 59.5 & 54 & 0.90 \\
ER+ subgroup & 50.5 & 62 & 0.02 \\
Histological grade, number & & & \\
1 & 4 & 13 & \\
2 & 10 & 9 & \\
3 & 5 & 8 & $0.19^{\mathrm{a}}$ \\
Median tumor size, millimeters & 15 & 14 & $0.67^{\mathrm{b}}$
\end{tabular}

Only cases from inclusion 1 are included. aFisher exact test. bWilcoxon rank sum test. ER, = estrogen receptor; LR-RT'= no local recurrence, no radiotherapy given; $\mathrm{LR}^{+} \mathrm{RT}^{-}=$local recurrence developed, no radiotherapy given.

local recurrence despite radiotherapy (indicating radio-resistance) is more homogeneous than the one associated with distant recurrences. It is believed that the development of metastases is a more complicated process and that different groups of genes may be of variable importance in distinguished subgroups of breast cancer.

\section{Conclusion}

We have found a very promising gene expression profile for predicting local recurrence despite radiotherapy - a profile that might be associated with radio-resistance. The signature provides substantially added value to the conventional factors used to predict risk of local recurrence. If confirmed in further studies, this profile might be a most important tool in the decision making for type of surgery and adjuvant therapy.

\section{Competing interests}

The authors declare that they have no competing interests.

\section{Authors' contributions}

EN-M participated in conceiving the design of the study, collecting the patient material and information of basic patient and tumor characteristics and clinical follow-up, performing gene expression and statistical analyses, interpreting data, and writing the paper. MK and CP participated in conceiving the design of the study, performing gene expression and statistical analyses, interpreting data, and writing the paper. EN-M and MK contributed equally to this manuscript. PM participated in conceiving the design of the study, collecting the patient material and information of basic patient and tumor characteristics and clinical follow-up, interpreting data, and writing the paper. CS participated in performing gene expression and statistical analyses, interpreting data, and writing the paper. IF, PK, BN, and OS participated in collecting the patient material and information of basic patient and tumor characteristics and clinical follow-up. GÖ re-evaluated the histopathological parameters. MF participated in conceiving the design of the study, interpreting data, and writing the paper. All authors read and approved the final manuscript.

\section{Acknowledgements}

We are indebted to participating departments of the South, West, South-East Sweden, and Stockholm Breast Cancer Group for providing samples and clinical follow-up. We especially thank Dorthe Grabau for re-evaluation of histological grade and Dick Killander for fruitful discussions at early stages of the study. The study was supported by funds from the Swedish Cancer Society, the Swedish Research Council, the Swedish Foundation for Strategic Research, the Gunnar, Arvid, and Elisabeth Nilsson Foundation, the Mrs Berta Kamprad Foundation, the University Hospital of Lund Research Foundation, the Knut Alice

Wallenberg Foundation through the Swegene consortium, the Strategic Science Foundation CREATE Health Centre, Skane County Council's Research and Development Foundation, and Governmental Funding of Clinical Research within the Nation Health Service.

\section{References}

1. Early Breast Cancer Trialists' Collaborative Group: Effects of chemotherapy and hormonal therapy for early breast cancer on recurrence and 15-year survival: an overview of the randomised trials. Lancet 2005, 365:1687-1717.

2. Voogd $A C$, Nielsen $M$, Peterse JL, Blichert-Toft $M$, Bartelink $H$, Overgaard M, van Tienhoven G, Andersen KW, Sylvester RJ, van Dongen JA: Differences in risk factors for local and distant recurrence after breast-conserving therapy or mastectomy for stage I and II breast cancer: pooled results of two large European randomized trials. J Clin Oncol 2001, 19:1688-1697.

3. Fredriksson I, Liljegren G, Palm-Sjövall M, Arnesson LG, Emdin $\mathrm{SO}$, Fornander $\mathrm{T}$, Lindgren $\mathrm{A}$, Nordgren $\mathrm{H}$, Idvall I, Holmqvist $\mathrm{M}$, Holmberg L, Frisell J: Risk factors for local recurrence after breast-conserving surgery. Br J Surg 2003, 90:1093-1102.

4. Leopold KA, Recht A, Schnitt SJ, Connolly JL, Rose MA, Silver B Harris JR: Results of conservative surgery and radiation therapy for multiple synchronous cancers of one breast. Int $J$ Radiat Oncol Biol Phys 1989, 16:11-16.

5. Kurtz JM, Jacquemier J, Amalric R, Brandone H, Ayme Y, Hans D, Bressac C, Spitalier JM: Breast-conserving therapy for macroscopically multiple cancers. Ann Surg 1990, 212:38-44.

6. Jacquemier J, Kurtz JM, Amalric R, Brandone H, Ayme Y, Spitalier $\mathrm{JM}$ : An assessment of extensive intraductal component as a risk factor for local recurrence after breast-conserving therapy. Br J Cancer 1990, 61:873-876.

7. Jobsen JJ, Palen J van der, Meerwaldt JH: The impact of age on local control in women with pT1 breast cancer treated with conservative surgery and radiation therapy. Eur $J$ Cancer 2001, 37:1820-1827.

8. Magee B, Swindell R, Harris M, Banerjee SS: Prognostic factors for breast recurrence after conservative breast surgery and radiotherapy: results from a randomised trial. Radiother Oncol 1996, 39:223-227.

9. Borger J, Kemperman $\mathrm{H}$, Hart A, Peterse H, van Dongen J, Bartelink $\mathrm{H}$ : Risk factors in breast-conservation therapy. J Clin Oncol 1994, 12:653-660.

10. Cheng SH, Horng CF, Clarke JL, Tsou MH, Tsai SY, Chen CM, Jian JJ, Liu MC, West M, Huang AT, Prosnitz LR: Prognostic index score and clinical prediction model of local regional recurrence after mastectomy in breast cancer patients. Int J Radiat Oncol Biol Phys 2006, 64:1401-1409.

11. Liljegren $G$, Lindgren A, Bergh J, Nordgren $H$, Tabar L, Holmberg $\mathrm{L}$ : Risk factors for local recurrence after conservative treat- 
ment in stage I breast cancer. Definition of a subgroup not requiring radiotherapy. Ann Oncol 1997, 8:235-241.

12. van't Veer LJ, Dai H, Vijver MJ van de, He YD, Hart AA, Mao M, Peterse HL, Kooy K van der, Marton MJ, Witteveen AT, Schreiber GJ, Kerkhoven RM, Roberts C, Linsley PS, Bernards R, Friend SH: Gene expression profiling predicts clinical outcome of breast cancer. Nature 2002, 415:530-536.

13. Vijver MJ van de, He YD, van't Veer LJ, Dai H, Hart AA, Voskuil DW, Schreiber GJ, Peterse JL, Roberts C, Marton MJ, Parrish M, Atsma D, Witteveen A, Glas A, Delahaye L, Velde T van der, Bartelink H, Rodenhuis S, Rutgers ET, Friend SH, Bernards R: A geneexpression signature as a predictor of survival in breast cancer. N Engl J Med 2002, 347:1999-2009.

14. Wang Y, Klijn JG, Zhang Y, Sieuwerts AM, Look MP, Yang F, Talantov D, Timmermans M, Meijer-van Gelder ME, Yu J, Jatkoe T, Berns EM, Atkins D, Foekens JA: Gene-expression profiles to predict distant metastasis of lymph-node-negative primary breast cancer. Lancet 2005, 365:671-679.

15. Perou CM, Sørlie T, Eisen MB, Rijn M van de, Jeffrey SS, Rees CA, Pollack JR, Ross DT, Johnsen H, Akslen LA, Fluge O, Pergamenschikov A, Williams C, Zhu SX, Lønning PE, Børresen-Dale AL, Brown PO, Botstein D: Molecular portraits of human breast tumours. Nature 2000, 406:747-752.

16. Sørlie T, Perou CM, Tibshirani R, Aas T, Geisler S, Johnsen H, Hastie T, Eisen MB, Rijn M van de, Jeffrey SS, Thorsen T, Quist $H$, Matese JC, Brown PO, Botstein D, Eystein Lønning P, BørresenDale AL: Gene expression patterns of breast carcinomas distinguish tumor subclasses with clinical implications. Proc Natl Acad Sci USA 2001, 98:10869-10874.

17. Sorlie T, Tibshirani R, Parker J, Hastie T, Marron JS, Nobel A, Deng $\mathrm{S}$, Johnsen H, Pesich R, Geisler S, Demeter J, Perou CM, Lønning PE, Brown PO, Børresen-Dale AL, Botstein D: Repeated observation of breast tumor subtypes in independent gene expression data sets. Proc Natl Acad Sci USA 2003, 100:8418-8423.

18. Cheng $\mathrm{SH}$, Horng CF, West $\mathrm{M}$, Huang $\mathrm{E}$, Pittman J, Tsou $\mathrm{MH}$, Dressman H, Chen CM, Tsai SY, Jian JJ, Liu MC, Nevins JR, Huang AT: Genomic prediction of locoregional recurrence after mastectomy in breast cancer. J Clin Oncol 2006, 24:4594-4602.

19. Kreike B, Halfwerk $H$, Kristel $P$, Glas A, Peterse $H$, Bartelink $H$, Vijver MJ van de: Gene expression profiles of primary breast carcinomas from patients at high risk for local recurrence after breast-conserving therapy. Clin Cancer Res 2006, 12:5705-5712.

20. Nuyten DS, Kreike B, Hart AA, Chi JT, Sneddon JB, Wessels LF, Peterse HJ, Bartelink H, Brown PO, Chang HY, Vijver MJ van de: Predicting a local recurrence after breast-conserving therapy by gene expression profiling. Breast Cancer Res 2006, 8:R62.

21. Chang HY, Sneddon JB, Alizadeh AA, Sood R, West RB, Montgomery K, Chi JT, Rijn M van de, Botstein D, Brown PO: Gene expression signature of fibroblast serum response predicts human cancer progression: similarities between tumors and wounds. PLoS biology 2004, 2:E7.

22. Gruvberger S, Ringner M, Chen $Y$, Panavally $S$, Saal LH, Borg A, Ferno M, Peterson C, Meltzer PS: Estrogen receptor status in breast cancer is associated with remarkably distinct gene expression patterns. Cancer Res 2001, 61:5979-5984.

23. Sotiriou C, Neo SY, McShane LM, Korn EL, Long PM, Jazaeri A, Martiat P, Fox SB, Harris AL, Liu ET: Breast cancer classification and prognosis based on gene expression profiles from a population-based study. Proc Natl Acad Sci USA 2003, 100:10393-10398.

24. Teschendorff AE, Naderi A, Barbosa-Morais NL, Pinder SE, Ellis $\mathrm{IO}$, Aparicio S, Brenton JD, Caldas C: A consensus prognostic gene expression classifier for ER positive breast cancer. Genome Biol 2006, 7:R101.

25. Malmström P, Holmberg L, Anderson H, Mattsson J, Jönsson PE, Tennvall-Nittby L, Balldin G, Lovén L, Svensson JH, Ingvar C, Möller T, Holmberg E, Wallgren A, Swedisj Breast Cancer Group: Breast conservation surgery, with and without radiotherapy, in women with lymph node-negative breast cancer: a randomised clinical trial in a population with access to public mammography screening. Eur J Cancer 2003, 39:1690-1697.

26. Fredriksson I, Liljegren G, Arnesson LG, Emdin SO, Palm-Sjovall $\mathrm{M}$, Fornander T, Frisell J, Holmberg L: Time trends in the results of breast conservation in $\mathbf{4 6 9 4}$ women. Eur J Cancer 2001, 37:1537-1544
27. Elston C, Ellis I: Assessment of histological grade. In Systemic Pathology Volume 13. 3rd edition. London: Churchill Livingstone; 1998.

28. Strand C, Enell J, Hedenfalk I, Ferno M: RNA quality in frozen breast cancer samples and the influence on gene expression analysis - a comparison of three evaluation methods using microcapillary electrophoresis traces. BMC Mol Biol 2007, 8:38.

29. Schroeder A, Mueller O, Stocker S, Salowsky R, Leiber M, Gassmann M, Lightfoot S, Menzel W, Granzow M, Ragg T: The RIN: an RNA integrity number for assigning integrity values to RNA measurements. BMC Mol Biol 2006, 7:3.

30. Jönsson G, Naylor TL, Vallon-Christersson J, Staaf J, Huang J Ward MR, Greshock JD, Luts L, Olsson H, Rahman N, Stratton M, Ringnér $M$, Borg A, Weber BL: Distinct genomic profiles in hereditary breast tumors identified by array-based comparative genomic hybridization. Cancer Res 2005, 65:7612-7621.

31. Cristianini N, Shawe-Taylor J: An Introduction to Support Vector Machines and Other Kernel-Based Learning Methods Cambridge, UK: Cambridge University Press; 2000.

32. Ihaka R, Gentleman R: A language for data analysis and graphics. J Comp Graph Stat 1996, 5:299-314.

33. The Gene Ontology homepage [http://www.geneontology.org]

34. Ringner M, Veerla S, Andersson S, Staaf J, Hakkinen J: ACID: a database for microarray clone information. Bioinformatics 2004, 20:2305-2306.

35. Breslin $\mathrm{T}$, Eden $\mathrm{P}$, Krogh $\mathrm{M}$ : Comparing functional annotation analyses with Catmap. BMC Bioinformatics 2004, 5:193.

36. Benjamini $Y$, Hochberg $Y$ : Controlling the false discovery rate: a practical and powerful approach to multiple testing. J $R$ Stat Soc Ser B 1995, 57:289-300.

37. Touboul E, Buffat L, Belkacémi $Y$, Lefranc JP, Uzan $S$, Lhuillier $P$ Faivre C, Huart J, Lotz JP, Antoine M, Pène F, Blondon J, Izrael V, Laugier A, Schlienger M, Housset M: Local recurrences and distant metastases after breast-conserving surgery and radiation therapy for early breast cancer. Int J Radiat Oncol Biol Phys 1999, 43:25-38.

38. Fortin A, Larochelle M, Laverdiere J, Lavertu S, Tremblay D: Local failure is responsible for the decrease in survival for patients with breast cancer treated with conservative surgery and postoperative radiotherapy. J Clin Oncol 1999, 17:101-109.

39. Clarke M, Collins R, Darby S, Davies C, Elphinstone P, Evans E, Godwin J, Gray R, Hicks C, James S, MacKinnon E, McGale P McHugh T, Peto R, Taylor C, Wang Y, Early Breast Cancer Trialists' Collaborative Group (EBCTCG): Effects of radiotherapy and of differences in the extent of surgery for early breast cancer on local recurrence and 15-year survival: an overview of the randomised trials. Lancet 2005, 366:2087-2106.

40. Eden P, Ritz C, Rose C, Ferno M, Peterson C: 'Good Old' clinical markers have similar power in breast cancer prognosis as microarray gene expression profilers. Eur J Cancer 2004, 40:1837-1841.

41. Fisher B, Anderson S, Redmond CK, Wolmark N, Wickerham DL, Cronin WM: Reanalysis and results after 12 years of follow-up in a randomized clinical trial comparing total mastectomy with lumpectomy with or without irradiation in the treatment of breast cancer. N Engl J Med 1995, 333:1456-1461.

42. Veronesi U, Salvadori B, Luini A, Greco M, Saccozzi R, del Vecchio $M$, Mariani L, Zurrida S, Rilke F: Breast conservation is a safe method in patients with small cancer of the breast. Long-term results of three randomised trials on 1,973 patients. Eur $J$ Cancer 1995, 31A:1574-1579.

43. Bartelink $\mathrm{H}$, Horiot $\mathrm{JC}$, Poortmans $\mathrm{P}$, Struikmans $\mathrm{H}$, Bogaert $\mathrm{W}$ Van den, Barillot I, Fourquet A, Borger J, Jager J, Hoogenraad W Collette L, Pierart M, European Organization for Research and Treatment of Cancer Radiotherapy and Breast Cancer Groups: Recurrence rates after treatment of breast cancer with standard radiotherapy with or without additional radiation. $N$ Engl J Med 2001, 345:1378-1387.

44. Bartelink H, Horiot JC, Poortmans PM, Struikmans H, Bogaert W Van den, Fourquet A, Jager JJ, Hoogenraad WJ, Oei SB, WárlámRodenhuis CC, Pierart M, Collette L: Impact of a higher radiation dose on local control and survival in breast-conserving therapy of early breast cancer: 10-year results of the randomized boost versus no boost EORTC 22881-10882 trial. J Clin Oncol 2007, 25:3259-3265. 